\title{
A METHODOLOGY TO SUPPORT COMPANIES IN THE FIRST STEPS TOWARDS DE-MANUFACTURING
}

\author{
Cappelletti, Federica; \\ Rossi, Marta; \\ Germani, Michele; \\ Hanif, Mohammad Shadman \\ Università Politecnica delle Marche
}

\begin{abstract}
De-manufacturing and re-manufacturing are fundamental technical solutions to efficiently recover value from post-use products. Disassembly in one of the most complex activities in de-manufacturing because i) the more manual it is the higher is its cost, ii) disassembly times are variable due to uncertainty of conditions of products reaching their EoL, and iii) because it is necessary to know which components to disassemble to balance the cost of disassembly. The paper proposes a methodology that finds ways of applications: it can be applied at the design stage to detect space for product design improvements, and it also represents a baseline from organizations approaching demanufacturing for the first time. The methodology consists of four main steps, in which firstly targets components are identified, according to their environmental impact; secondly their disassembly sequence is qualitatively evaluated, and successively it is quantitatively determined via disassembly times, predicting also the status of the component at their End of Life. The aim of the methodology is reached at the fourth phase when alternative, eco-friendlier End of Life strategies are proposed, verified, and chosen.
\end{abstract}

Keywords: Demanufacturing, Circular economy, Ecodesign, Mechatronics, EoL strategies.

\section{Contact:}

Rossi, Marta

Università Politecnica delle Marche

Department of Industrial Engineering and Mathematical Sciences

Italy

marta.rossi@univpm.it 


\section{INTRODUCTION AND STATE OF THE ART}

De-manufacturing and re-manufacturing are fundamental technical solutions for an efficient and systematic implementation of the Circular Economy. More formally, de-manufacturing includes the set of technologies and systems, tools, and knowledge-based methods to systematically recover, reuse, and upgrade functions and materials from industrial waste and post-consumer products (Tolio et al. 2017). Although de-manufacturing occurs at the End of Life $(\mathrm{EoL})$ of a product lifecycle, very far in time (and sometimes space) from when (and where) the design process takes place, it is essential to establish a link that connects the two phases, so that design improves the product also by implementing suggestions and feedbacks from the EoL. Up to now, there have been established regulations and directives to move up the focus of waste management to the design stage (i.e. ROHS (Parliament and Council, 2011) or WEEE (Parliament and Council, 2012) directive, ELV (Parliament and Council, 2013), but they still not concern all the products. Nevertheless, from one side there is the consciousness of organizations, that soon also other product categories will be called to be more circular and eco-friendlier. On the other hand, several barriers exist to the implementation of these strategies in the industrial context, e.g. lack of internal awareness, lack of knowledge, lack of incentives, lack of feedback channels, and non-supportive organizational structures (Haziri et al. 2019).

In literature, several authors proposed to consider EoL recovery strategies and lifecycle issues as essential inputs/factors in product design. Fargnoli et al. (2012) examined the incorporation of Product Service System approach in design activities, underlining its role in increasing recycling and reuse opportunities. Other authors presented very complex algorithms (Mangun and Thurston, 2002), mixedinteger programming models (Kwak and Kim, 2011), mining-based optimization model (Ma et al. 2014), and predictive and dynamic models to find optimal settings of product attributes (Ma et al. 2014; Aydin et al. 2015) for EoL phase optimization. Some approaches have been developed to model the timevarying value of a product (Kwak and Kim, 2011; Xing, K. and Luong, 2009; Kumar et al. 2007).

Others focused on specific products and the evaluation of environmental benefits related to the implementation of different EoL strategies, e.g. smartphone cases (Andrae, 2016, Zink et al. 2014). Badurdeen et al. (2018) proposed a methodology for configuration design to optimize products over multiple lifecycles while considering economic and environmental objectives. These are very complex methodologies, difficult to implement inside design departments and directly by designers. On the other side, several works focused on a specific aspect of de-manufacturing, e.g. disassembly strategies aimed at materials recycling (Williams, 2007), disassembly sequences for products (Cappelli et al. 2007; Favi et al. 2019; Harivardhini et al. 2017), oriented graphs, and constraint matrices, like those used in this paper (Belhadj et al. 2019; Smith and Hung, 2015). Graphical techniques are useful to detect the disassembly sequence and are at the basis of the disassembly time calculation (Frizziero et al. 2019) and the subsequent evaluation of the feasibility of the disassembly (Peeters et al. 2015), but it is necessary to associate them with other considerations (e.g. environmental benefits of EoL strategies).

This paper, with the proposed methodology, will help all companies that autonomously are approaching de-manufacturing as the first step before implementing a circular business. It distinguishes from existing literature in the following three main points. It integrates information of product disassembly level and component status at their EoL, with environmental feedbacks, through an easy-to-apply procedure. It overcomes the complexity of actual methodologies proposed in the literature, due to the fact a large amount of information required is contained in the product bill of materials and virtual model, making it usable in the industrial design context. Furthermore, it allows integrating feedbacks coming from EoL strategies evaluation (through environmental analysis) into the design process, as suggested in Haziri et al. (2019) enabling the designer to identify product optimization strategies.

\section{METHODOLOGY}

The methodology comes from the need to reduce waste and treat components at their EoL as new resources. It aims at identifying the best EoL strategy for target components. Target components are selected according to their environmental impact (i.e. most impacting components). The following sub-sections will explain the main steps of the methodology and the relative flow of information, also depicted in Figure 1; these are:

1. Preliminary Life Cycle Analysis (LCA);

2. Qualitative disassembly analysis; 
3. Quantitative disassembly analysis;

4. EoL strategies analysis.

The proposed methodology uses some approaches and formulas already proposed by the literature. In particular, for disassembly sequences analysis and disassembly time, it follows approaches proposed by Mandolini et al. (2018), Favi et al. (2019), while for the calculation of EoL indices, it follows the methodology proposed by Ardente and Wolf (2011). They have been integrated each other's and with the LCA methodology and tools and allows both companies to obtain a complete overview of components' EoL performances and designer to derive strategies for product EoL optimization.

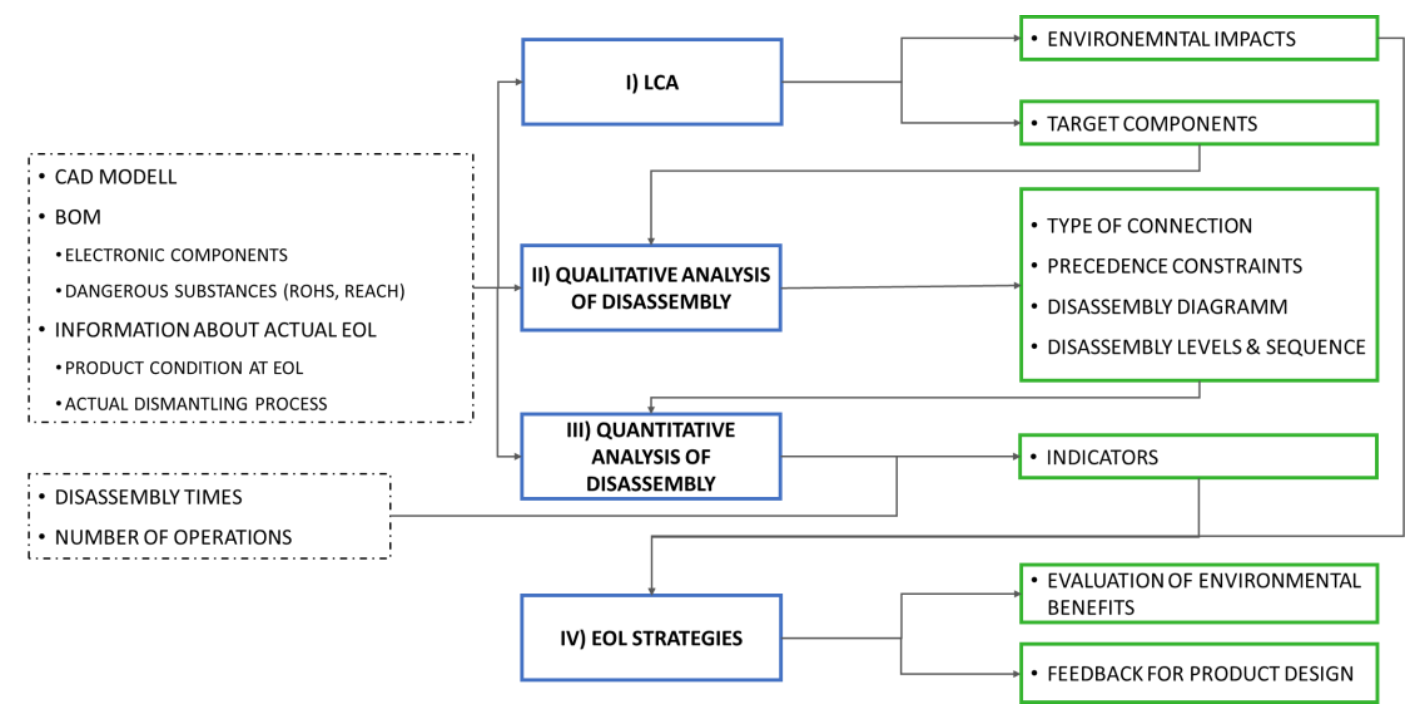

Figure 1. Methodology scheme and information flow.

The environmental impact is a differential analysis and does not consider the use phase, which is assumed to be the same for different EoL scenarios. The dotted boxes in Figure 1 show the external inputs required to apply the methodology:

1. The Bill of materials, including materials and manufacturing processes;

2. CAD model (from which you get information about geometry, dimensions, joining elements, etc.); the 3D model is useful to derive the disassembly sequence and identify precedencies, interferences, relative locations, etc);

3. Information about the status of the product at the EoL;

4. Current dismantling process;

5. Information about dangerous substances, according to ROHS directive and REACH regulation.

\subsection{Preliminary LCA}

The preliminary LCA aims at identifying the most impactful components also referred to as target components. The next phases will be simple and fast because they focus only on target components, which are a limited number of the total elements of a product. The system boundaries include the material and manufacturing phases, and the EoL phase, which are the only affected by de/remanufacturing strategies. When evaluating the environmental impacts it is advisable to choose a method with multiple indicators, so that target components will be chosen according to criticalities related to more than one indicator.

\subsection{Qualitative disassembly analysis}

This phase is useful to inspect the product and identify a possible disassembly sequence through a topdown approach. First identifying sub-assemblies and gathering components in groups may be very useful to simplify the disassembly analysis. After that, all types of connections (i.e. fixed/movable, permanent/temporary, allowing/not allowing movement, etc.) must be examined with dual scope: understand how to disassemble the groups and to pave the way to the quantitative analysis. This may be done through the help of a CAD model. Once is clear how to disassemble the sub-assemblies, each of them is analysed to identify the remaining disassembly sequence to take apart each component. The disassembly time can be summarised in an oriented graph, where knots contain components and/or 
sub-assemblies and arrows show the precedence constraints. Sometimes it is difficult to represent a complex product via the oriented graph, so the authors suggest also using the constraint matrix. This matrix, also known as the level matrix (Mandolini et al. 2018), is manually defined and it is an $n \times n$ square matrix, where $n$ is the number of components, inserted in rows and columns. Mandolini et al. (2018) suggest not to count the liaison and joining elements as components so they do not need to be extrapolated from the virtual models; in this methodology, thanks to the preliminary LCA it is very likely that liaisons and joints are neglected, together with few other not impacting parts. The matrix is populated according to the Boolean rule (1):

$$
x_{i j}=\left\{\begin{array}{l}
1 \text { if the } i_{\text {th }} \text { component is constrained by } j_{t h} \text { component } \\
0 \text { if } i_{\text {th }} \text { component is NOT constrained by } j_{t h} \text { component }
\end{array}, i \neq j\right.
$$

Figure 2 shows an example of graph-oriented and constraint matrix of a product made of 6 components/ sub-assemblies: before removing component 2 you must separate components 1,3 , and 4. The matrix is computer-editable, for this reason is advisable to always convert the oriented graph into the matrix, as suggested also by Luo et al. (2016). The first and second steps can be carried out simultaneously to reduce the analysis time.

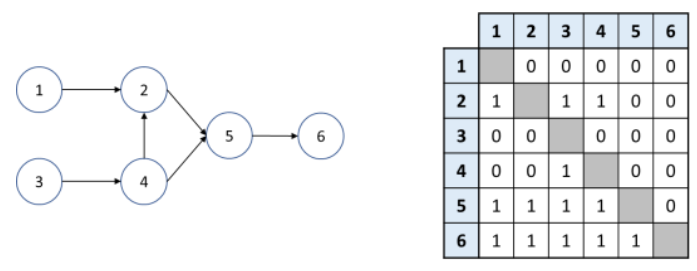

Figure 2. Example of an oriented graph and a level matrix.

\subsection{Quantitative disassembly analysis}

This step aims at quantifying the target components' disassembly time and the percentage of recoverable materials; besides the outcomes of the previous phase, this also requires the disassembly time of liaisons to obtain as output indicators useful at the design stage to improve the product features and to choose the best EoL strategies.

\subsubsection{Disassembly levels}

This sub-phase aims at defining the disassembly level and verifying the disassembly sequence. A disassembly level is defined as the level in which one or more components/subassemblies connected to other components/subassemblies can be disassembled without any physical obstruction (Mandolini et al. 2018). In practice, this consists in re-organizing the rows of the level matrix in a way that the subtotals of all values in a row are arranged in ascending order. Parts belonging to the $i_{\text {th }}$ level can be disassembled after all parts till level $(i-1)_{t h}$ are removed. Figure 3 shows the levels obtained by the previous example. Now you can verify whether the previously assumed sequence is correct.

\begin{tabular}{|c|c|c|c|c|c|c|c|c|c|c|c|c|c|c|c|c|c|}
\hline & 1 & 2 & 3 & 4 & 5 & 6 & $\Sigma$ & & & 1 & 2 & 3 & 4 & 5 & 6 & $\Sigma$ & LEVEL \\
\hline 1 & & 0 & 0 & 0 & 0 & 0 & 0 & \multirow{6}{*}{$\Rightarrow$} & 1 & & 0 & 0 & 0 & 0 & 0 & 0 & \multirow{2}{*}{0} \\
\hline 2 & 1 & & 1 & 1 & 0 & 0 & 3 & & 3 & 0 & 0 & & 0 & 0 & 0 & 0 & \\
\hline 3 & 0 & 0 & & 0 & 0 & 0 & 0 & & 4 & 0 & 0 & 1 & & 0 & 0 & 1 & 1 \\
\hline 4 & 0 & 0 & 1 & & 0 & 0 & 1 & & 2 & 1 & & 1 & 1 & 0 & 0 & 3 & 2 \\
\hline 5 & 1 & 1 & 1 & 1 & & 0 & 4 & & 5 & 1 & 1 & 1 & 1 & & 0 & 4 & 3 \\
\hline 6 & 1 & 1 & 1 & 1 & 1 & & 5 & & 6 & 1 & 1 & 1 & 1 & 1 & & 5 & 4 \\
\hline
\end{tabular}

Figure 3. Disassembly level definition.

\subsubsection{Disassembly time}

For this step authors followed the procedure suggested by Mandolini et al. (2018) and interrogated the Lean DfD database (Favi et al. 2019). The method is based on the classification and characterization of joining elements, to which a standard disassembly time is assigned; this will be then adjusted, considering wear, corrosion, deformation, tools of disassembly, geometrical dimensions, etc. Time for material movement and tool changing is neglected. Equations (2) and (3) show how the disassembly time of a component is calculated and adjusted with corrective factors. 


$$
T_{\text {dis }}=\sum_{j=1}^{n} T_{o p_{j}}=\sum_{j=1}^{n}\left(m \cdot T_{s} \cdot \prod_{k} C F_{k}\right)_{i}
$$

- $\quad T_{\text {dis }}$ is the time needed to take apart one or more liaisons of the same typology that you find between two components/sub-assemblies;

- $T_{o p_{j}}: j_{t h}$ operation disassembly time [s];

- $\quad m$ : number of $j$ joining elements;

- $\quad T_{s}$ : standard disassembly time [s];

- $C F_{k}$ : corrective factor depending on the characteristic of the joining element.

\subsubsection{Reusability and recyclability indicators}

Indicators are useful to compare different products and to choose the best EoL strategies; the first indicator (3) is the reusability rate and represents the percentage (in weight) of the product that is potentially reusable (Ardente and Wolf, 2011):

$$
R_{\text {Reuse }}=\frac{\sum_{i} \sum_{k} m_{\text {reuse }_{i, k}}}{m_{\text {tot }}} \cdot 100=\frac{\sum_{i} \sum_{k} m_{i, k} \cdot D_{i, k} \cdot M_{D_{i, k}}}{m_{\text {tot }}} \cdot 100
$$

- $m_{\text {tot }}$ : the total mass of the target component $[\mathrm{kg}]$;

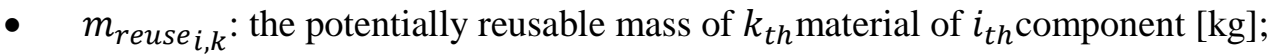

- $\quad m_{i k}$ : the reusable mass of $k_{t h}$ material of $i_{t h}$ component [kg];

- $\quad D_{i k}$ : disassemblability index of $k_{t h}$ material of $i_{t h}$ component [\%];

- $\quad M_{D_{i, k}}$ : degradation index of $k_{t h}$ material of $i_{t h}$ component [\%].

Please refer to (Ardente and Wolf, 2011) for tables and guidelines to calculate the disassemblability and degradation index; the latter one is the product of three sub-indices that consider the criticalities for reuse whenever the component do not accomplish critical technical standards and legislative requirements $\left(M_{D 1}\right)$, wear of the component, physical or chemical stress $\left(M_{D 2}\right)$ and the potential compromised functionalities due to an incorrect use $\left(M_{D 3}\right)$. Similarly, the recyclability index (4) is obtained as suggested by the same authors.

$$
R_{\text {Recycle }}=\frac{\sum_{i} \sum_{k} m_{\text {recycle }_{i, k}}}{m_{\text {tot }}} \cdot 100=\frac{\sum_{i} \sum_{k} m_{i, k} \cdot D_{i, k} \cdot M_{R_{i, k}} \cdot C^{\prime}{ }_{1, k}}{m_{\text {tot }}} \cdot 100
$$

- $m_{\text {tot }}$ : the total mass of the target component $[\mathrm{kg}]$;

- $\quad m_{\text {recycle }_{i, k}}$ : the potentially recyclable mass of $k_{t h}$ material of $i_{t h}$ component $[\mathrm{kg}]$;

- $\quad m_{i k}$ : the recyclable mass of $k_{t h}$ material of $i_{t h}$ component $[\mathrm{kg}]$;

- $\quad D_{i k}$ : disassemblability index of $k_{t h}$ material of $i_{t h}$ component [\%];

- $\quad M_{R}$ : recyclability index of $k_{t h}$ material of $i_{t h}$ component [\%];

- $\quad C_{1, k}^{\prime}$ : complementary contamination index of recyclable material [\%].

\subsection{EoL strategies}

The last test is finalized at identifying the best EoL strategy for each component; since its status tips the balance of decision, it has been chosen the degradation index as the crucial one. The degradation index evaluates how the components would reach the EoL. Three ranges have been set:

- $75-100 \%$ : if a component has a degradation index between $75 \%$ and $100 \%$ it can be re-used;

- 25-75\%: if a component has a degradation index between $25 \%$ and $75 \%$ it can be remanufactured;

- $0-25 \%$ : if a component has a degradation index between $0 \%$ and $25 \%$ it can be recycled.

If there are uncertainties related to the status of the component it is good to analyse more than one scenario and evaluate any difference in terms of environmental impacts.

To quantify the benefits deriving from the implementation of the new strategies, the percentage variation is calculated (5) as the difference of impacts of a certain category of the future $\left(V_{f}\right)$ and actual scenario $\left(V_{i}\right)$ over the impact of the same category of the actual scenario: 


$$
\Delta_{\text {env impact }}=\frac{V_{f}-V_{i}}{V_{i}} \cdot 100
$$

Three indexes (6-8) are then evaluated (derived from Ardente and Wolf, 2011); these are useful both for comparison and verification of compliance to regulations, such as WEEE (Parliament and Council, 2012).

$$
M_{\text {reuse }}=\frac{\sum_{i} m_{\text {reuse }_{i}}}{m_{\text {tot }}} ; M_{\text {reman. }}=\frac{\sum_{i} m_{\text {reman }_{. i}}}{m_{\text {tot }}} ; M_{\text {recycle }}=\frac{\sum_{i} m_{\text {recycle }_{i}}}{m_{\text {tot }}}
$$

- $m_{\text {reuse }_{i}}$ is the mass of the $i_{t h}$ component intended to be re-used [kg];

- $m_{\text {reman }}$ is the mass of the $i_{t h}$ component intended to be re-manufactured [kg];

- $\quad m_{\text {recycle }}$ is the mass of the $i_{t h}$ component intended to be recycled [kg].

Results coming from this last phase allow the evaluation of product EoL scenario performances in environmental terms. A double effect is generated: the company can understand the potential benefits of de/re-manufacturing strategies implementation and reflect on product criticalities. All components not suitable for de/remanufacturing strategies can be easily identified and providing designers feedbacks for their optimization.

\section{CASE STUDY}

The methodology presented has been applied in an academic case study that regarded a commercial good, produced by an Italian company, a world leader in the production of electro-spindles. The goal consisted of recovering as much value and components as possible out of the product. The company provided the BOM of the electro-spindle containing 259 elements, including 77 screws and 44 washers. Six main groups were identified:

- $\quad$ Group A: Cooling fan group;

- Group B: Pneumatic cylinder group (automatic tool changer system);

- $\quad$ Group C: Shaft kit (included rotor);

- Group D: Stator housing group (structural and thermal function);

- Group E: Sensors group (together with signal and power connectors).

To facilitate the analysis all their components have been numbered and, for more discretion, in this work, only the number of the component will be explicated.

\subsection{Preliminary LCA}

The preliminary LCA has been supported by SimaPro software (database Ecoinvent 3), and impacts were calculated with the ReCiPe Midpoint $(\mathrm{H})$ method. As shown in Figure 4, only six of the 18 impact categories have been selected: Climate change $\left[\mathrm{kg} \mathrm{CO}_{2}\right.$ eq], Freshwater eutrophication [kg P eq], Human toxicity [kg 14-DB eq], Freshwater ecotoxicity [kg 1,4-DB eq], Marine ecotoxicity [kg 1,4 - DB eq], Metal depletion [kg Fe eq].

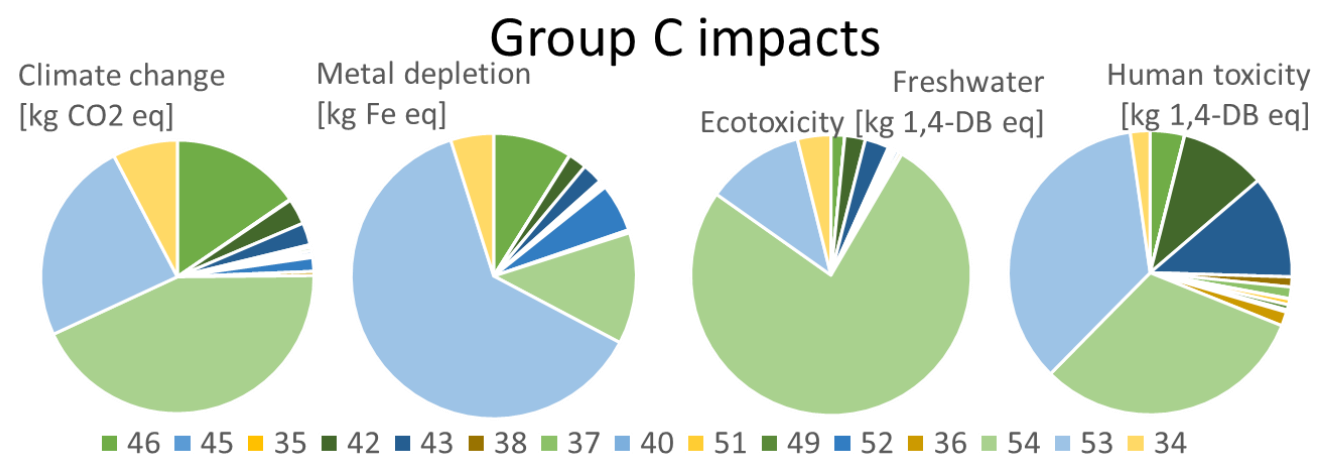

Figure 4. Impacts of group C, main impact categories.

Washers, o-rings and all elements lighter than 1 gr have been cut off. The use phase has been neglected since it is assumed equal for actual and future scenarios. At the moment at the EoL the spindle is mostly shredded, then metal and non-metals parts are destined for recycling; nevertheless, 
the process is not efficient from an environmental point of view. Figure 4 contains a graph that illustrates the impacts of group $\mathrm{C}$ for the selected categories. Similar considerations are carried out for each group of the electro-spindle, both for the material and manufacturing phase and EoL stage. The preliminary analysis outlined the 14 target components that will be further analysed; their weight in total is $88 \%$ of the total weight of the product.

\subsection{Qualitative disassembly analysis}

As suggested by the methodology this phase has been carried out simultaneously with the first step. To disassemble the electro-spindle you must act both from the front (where the tool is attached) and backside (where the fan is located). From the analysis of the CAD model and investigating the connectors, the oriented graph has been created; Figure 5 shows the oriented graph for group C. It has been then converted to the constraint matrix.

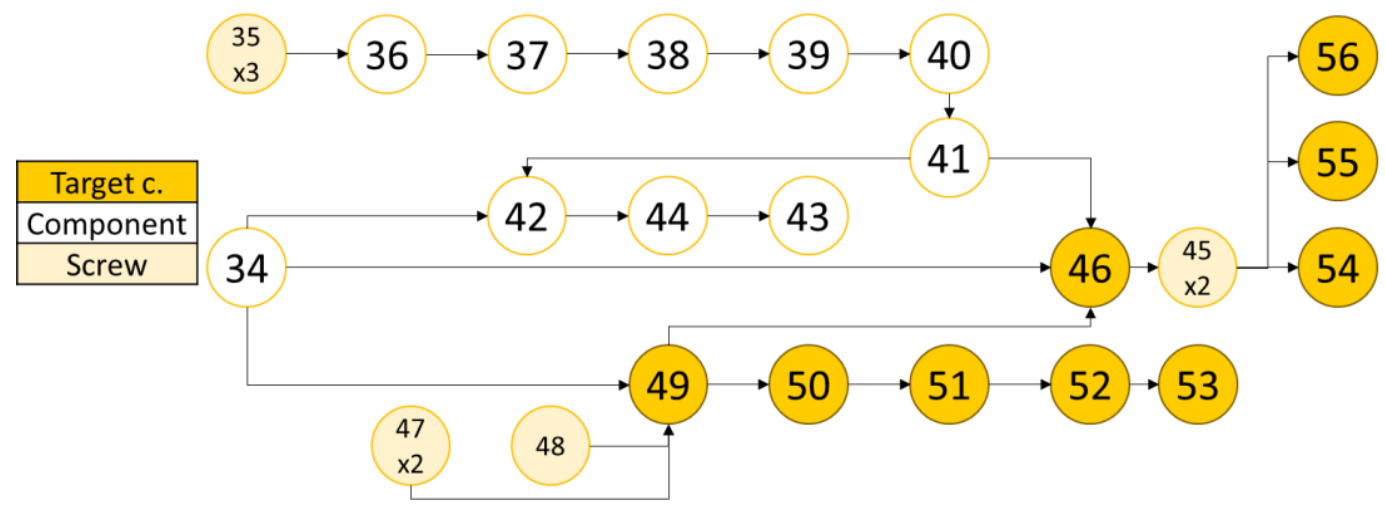

Figure 5. Oriented graph for disassembly of group C.

\subsection{QUANTITATIVE DISASSEMBLY ANALYSIS}

The matrix derived from the graph must be rearranged to get the level matrix; from this, according to the database of LeanDfD (Favi et al. 2019), all disassembly times were calculated. Figure 6 provides an example for Group C.

Once disassembly times and the number of operations were reasonably estimated, indexes were evaluated, according to the methodology advice and references.

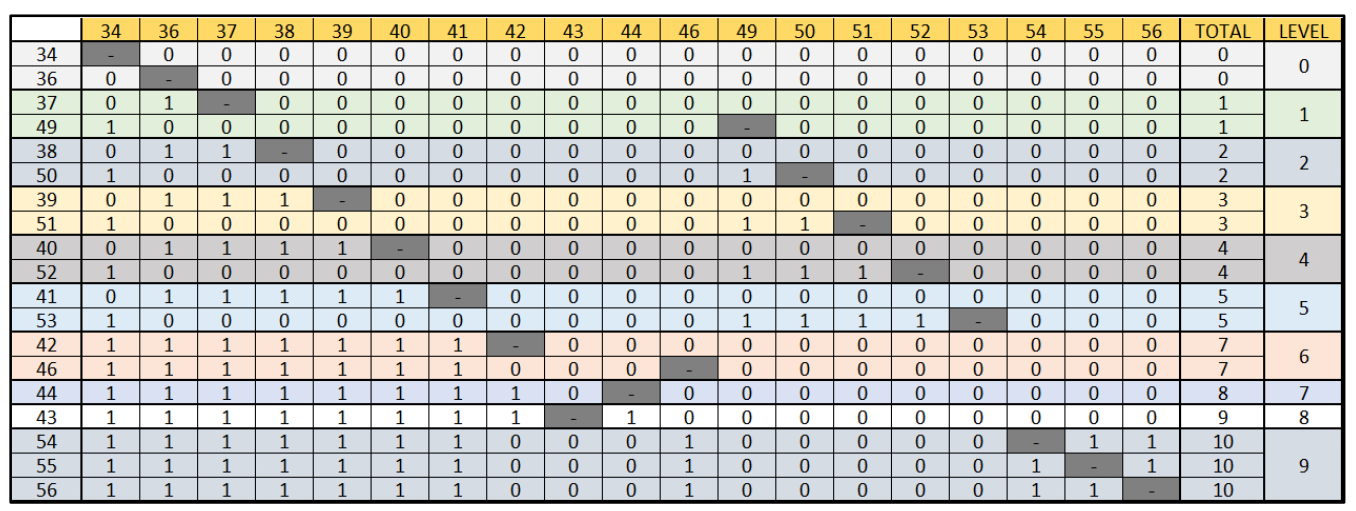

Figure 6. Level matrix of group $C$.

\subsection{EoL strategies}

According to the criteria suggested by the methodology, only components 12,63 , and 25 are re-usable, because they have a degradation index higher than $75 \%$ (Figure 7). It is worth noticing the assumption considered in this application: by re-using it is meant that the part is re-used as it is, with the same purpose it was first used. Only manual cleaning is applicable. It is reasonable to consider the recycling process for the components that do not undergo re-use or re-manufacturing because they will be disassembled, as they are target components, and because their $M_{D}$ is different from zero (meaning that they are not highly contaminated with incompatible or hazardous materials). The company is facing 
de-manufacturing topic for the first time; for this reason, re-manufacturing processes are not known yet. When modelling future scenarios in SimaPro, it is supposed that re-manufacturing activities consist in general metal processes that regard up to $50 \%$ of the total weight of the components. Both for re-used and re-manufactured parts, there is no material phase because any resources are not required to be extracted and worked.

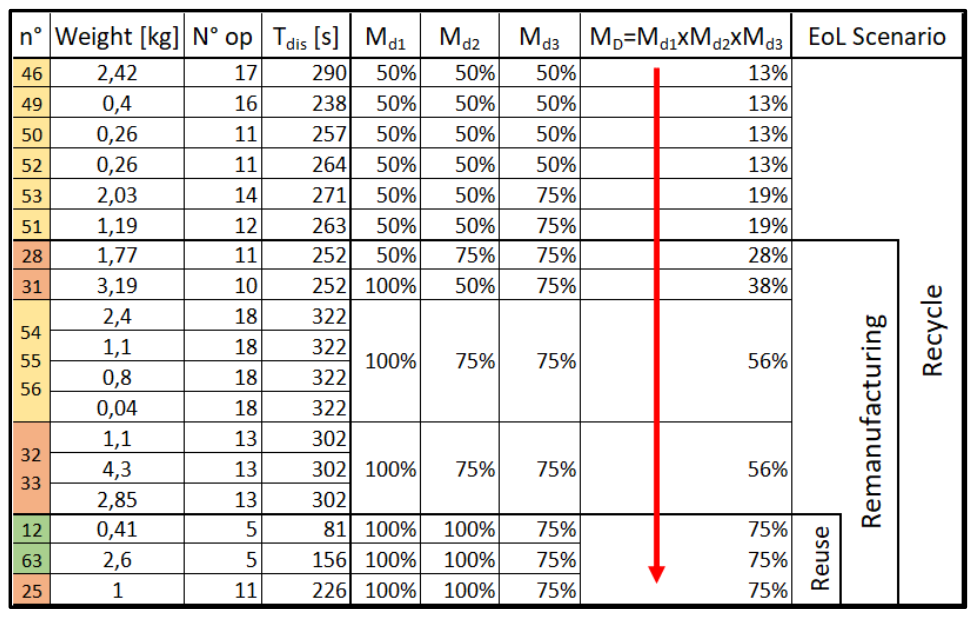

Figure 7. EoL future scenarios for the electro-spindle.

Three scenarios are modelled: i) the first one is the one depicted in Figure 7; ii) the second is a bit less optimistic and images that also components 12,63, and 25 are re-manufactured (this means that they reach their EoL in worse conditions than the first case); iii) in the third one all targets components are recycled. Results prove that re-using and re-manufacturing are much more environmentally sustainable than the actual EoL strategy; Figure 8 compares the overall impacts of actual and future scenarios. The overall impact of the product can be reduced up to $64 \%$ of $\mathrm{CO}_{2}$ eq; few indicators, such as freshwater and marine ecotoxicity, are in favour of the actual process; this may be due to the high quantity of electricity required for recycling processes.

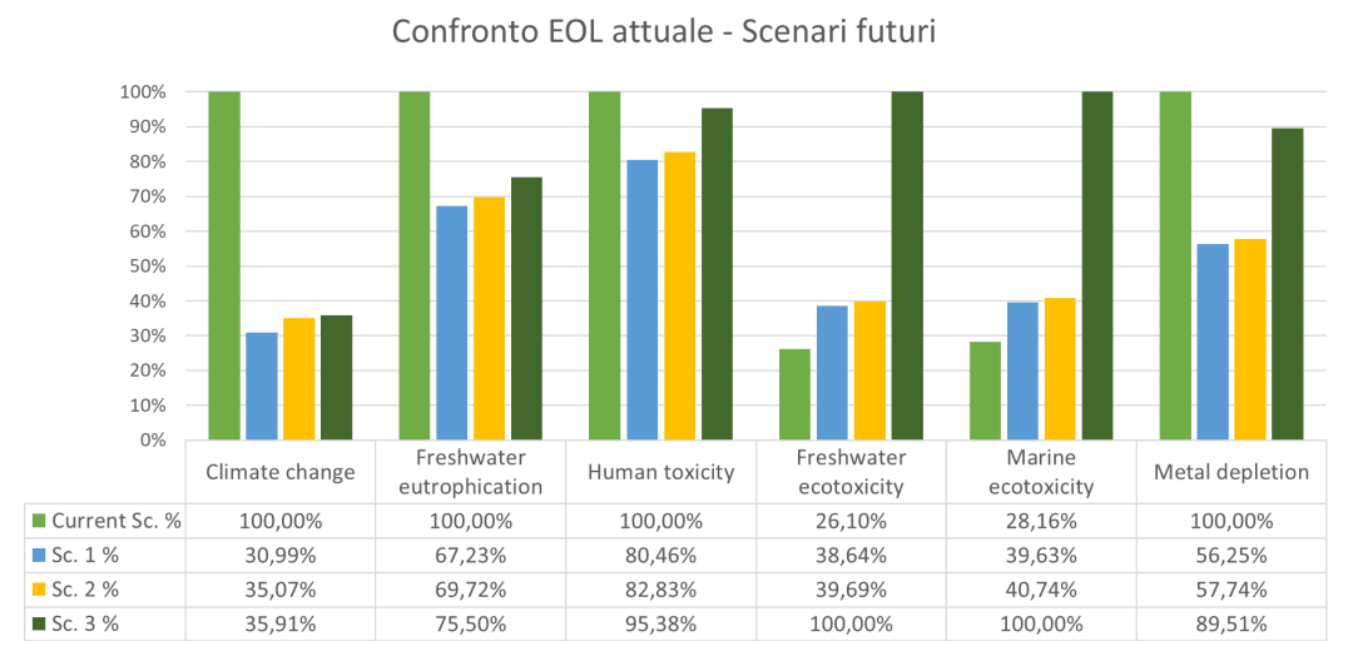

Figure 8. Comparison between actual EoL strategy and future scenarios.

The application of the methodology to the case study showed great potentialities and highlighted new, more sustainable EoL scenarios. When applying it in an industrial context, a validation procedure should be followed; in particular, the following aspects should be considered and analyzed:

- Resource availability: different profiles can participate and ease its implementation. Besides designers, an environmental expert can give support, especially on the first and the last steps, when an environmental evaluation is required. The maintenance responsible can give contribution when the disassembly sequence is generated, especially for his knowledge of components that are assembled in more than one product model. The production manager can 
support designers with the identification and validation of the target components and the new EoL scenarios;

- Acceptability: evaluate the obstacles encountered during the index calculation and if designers are willing to introduce the application of the methodology in the design process;

- Implementation time; this point concerns both the time needed to complete the four steps of the methodology once it is fully implemented in the design process and also how long it takes before the methodology can be considered completely integrated into the design process;

- Usefulness: the validation should consider the effectiveness and strength of the methodology both per se and compare to the usefulness of other similar methodologies;

- Cost-effectiveness: evaluate the advantages gained from the implementation of the methodology, compared to the resources employed; it is worth notice that the benefits related to the methodology do not only stand on the potential improvement of environmental impact related to the different EoL scenarios; through each step, the methodology can improve the knowledge of the product both from a technical point of view (useful for maintenance, manufacturing and de/re-manufacturing) and from an environmental one (the methodology helps to spread sustainability knowledge through departments) supporting the optimization of components environmental performances at their EoL;

- Integrability; evaluate if and how the inputs and outputs of the methodology can be integrated into the existing and used industrial tools (i.e. CAD software).

The case study will be implemented in an industrial context and the validation procedure will help in more deeply understanding the strengths and weaknesses of the methodology.

\section{CONCLUSION}

This work developed a methodology to tackle difficulties of managing and planning, since the early stage of design, the EoL strategy of a product. A methodology has been presented, structured in four main phases: i) identifying the most impacting components (target components); ii) determine the possible disassembly sequences and times; iii) calculate re-usability and recyclability indexes to understand difficulties related to de/re-manufacturing of the good; iv) find alternative EoL strategies to contain the environmental impacts. The methodology has been applied to an electro-spindle; at the moment when it reaches the EoL it is shredded and materials are sorted, although with non-efficient processes; the total disassembly time is about 8 minutes. The actual re-usability $(30,5 \%)$ and recyclability $(46,63 \%)$ indexes could be the baseline for further design improvements. The application of the methodology highlighted that re-using and re-manufacturing components highly improve the environmental performances of the product (up to $64 \% \mathrm{~kg} \mathrm{CO}_{2} \mathrm{eq}$ ), while recycling is most favourable to the actual process, but for certain indicators, it results to be more impacting due to high quantities of electricity required. Future works should focus on identifying the re-manufacturing activities; LCA and economic analysis should be approached next to the technical one, to verify whether the environmental considerations are aligned to the economic ones. Another interesting point to investigate is to collect information about the status of plenty of electro-spindle at their EoL, to create an empirical database. The presence of sensors and the activity of data-collecting would be much simplified if the good would be provided with embedded sensors and communicating systems to register use rate, faults, etc. and thus simplifying the inspection phase of the product.

\section{REFERENCES}

Andrae, A.S.G. (2016), "Life-cycle assessment of consumer electronics: a review of methodological approaches", Consumer Electronic Magazine, Vol. 5, pp. 51-60.

Ardente, F., Wolf, M-A., Mathieux, F. and Pennington, D. (2011), "Review of resource efficiency and end-oflife requirements. European Commission", Joint Research Centre, Institute for Environment and Sustainability. Deliverable 1.

Aydin, R., Kwong, C.K. and Ji, P. (2015), "A novel methodology for simultaneous consideration of remanufactured and new products in product line design", International Journal of Production Economics, Vol. 169, pp. 127-140.

Badurdeen, F., Aydin, R. and Brown, A. (2018), "A multiple lifecycle-based approach to sustainable product configuration design", Journal of Cleaner Production, Vol. 200, pp. 756-769.

Belhadj, I., Khemili, I., Trigui, M. and Aifaoui, N. (2019), "Time computing technique for wear parts dismantling”, International Journal of Advanced Manufacturing Technology, Vol. 103, pp. 3513-3527. 
Cappelli, F., Delogu, M., Pierini, M. and Schiavone, F. (2007), "Design for disassembly: A methodology for identifying the optimal disassembly sequence", Journal of Engineering Design, Vol. 18, pp. 563-575.

Fargnoli, M., De Minicis, M. and Tronci, M. (2012), "Product's life cycle modelling for ecodesign product service-system", International Design Conference.

Favi, C., Marconi, M., Germani, M. and Mandolini, M. (2019), “A design for disassembly tool oriented to mechatronic product de-manufacturing and recycling”, Advanced Engineering Informatics, Vol.39, pp. 6279. https://doi.org/10.1016/j.aei.2018.11.008.

Frizziero, L., Liverani, A., Caligiana, G., Donnici, G. and Chinaglia, L. (2019), "Design for disassembly (DfD) and augmented reality (AR): Case study applied to a gearbox”, Machines, Vol. 7 No. 2, pp. 7-29.

Harivardhini, S., Murali Krishna, K. and Chakrabarti, A. (2017), “An Integrated Framework for supporting decision making during early design stages on end-of-life disassembly", Journal of Cleaner Production, Vol. 168, pp. 558-574.

Haziri, L. L., Sundin, E. and Sakao, T. (2019), "Feedback from Remanufacturing: Its Unexploited Potential to Improve Future Product Design", Sustainability, Vol. 11, p. 4037; https://doi.org/10.3390/su11154037.

Johnson, M.R. and McCarthy, I.P. (2014), "Product recovery decisions within the context of Extended Producer Responsibility", Journal of Engineering and Technology Management, Vol. 34, pp. 9-28.

Kumar, V., Shirodkar, S., Camelio, J.A., and Sutherland, J.W. (2007), "Value Flow Characterization During Product Lifecycle to Assist in Recovery Decisions". International Journal of Production Research, Vol. 45, pp. 4555-4572.

Kwak, M. and Kim, H.M. (2011), "Assessing product family design from an end-of-life perspective" Engineering Optimization, Vol. 43 No 3, pp. 233-255.

Kwak, M. and Kim, H.M. (2011), "Modelling time-varying value of an end-of-life product for design for recovery", International Conference of Engineering Design.

Luo, Y., Peng, Q. and Gu, P. (2016), "Integrated multi-layer representation and ant colony search for product selective disassembly planning”, Computers in Industry, Vol. 75, pp. 13-26.

Ma, J., Kwak, M. and Kim, H.M. (2014), Demand trend mining for predictive life cycle design, Journal of Cleaner Production, Vol. 68, pp. 189-199.

Mandolini, M., Favi, C., Germani, M. and Marconi, M. (2018), "Time-based disassembly method: how to assess the best disassembly sequence and time of target components in complex products", The International Journal of Advanced Manufacturing Technology, Vol. 95 No. 1-4, pp. 409-430.

Mangun, D. and Thurston, D.L. (2002), "Incorporating component reuse, remanufacture, and recycle into product portfolio design", IEEE Trans. Eng. Manag., Vol. 49, pp. 479-490.

Parliament, E. and Council, U. (2011), "Directive 2011/65/eu of the european parliament and of the council of 8 June 2011 on", Fundamental Texts On European Private Law, pp. 88-110.

Parliament, E. and Council, U. (2012), "Directive 2012/19/eu of the european parliament and of the council of 4 July 2012 on waste electrical and electronic equipment (WEEE)", Official Journal of the European Union, No. June, pp. 38-71.

Parliament, E. and Council, U. (2013), "Directive 2000/53/ec of the european parliament and of the council of 18 September 2000 on end-of life vehicles", Official Journal of the European Union, No. L269, pp. 34-43.

Peeters, J.R., Vanegas, P., Dewulf, W. and Duflou, J.R. (2015), "Economic and environmental evaluation of fasteners for active disassembly: A case study for payment terminals", Procedia CIRP, Vol. 29, pp. 704709.

Smith, S. and Hung, P.Y. (2015), “A novel selective parallel disassembly planning method for green design”, Journal of Engineering Design, Vol. 26 No. 10-12, pp. 283-301.

Tolio, T., Bernard, A., Colledani, M., Kara, S., Seliger, G., Duflou, J., Battaia, O. (2017), "Design, management and control of demanufacturing and remanufacturing systems", CIRP Annals - Manufacturing Technology, Vol. 66 No. 2, pp. 585-609.

Williams, J.A.S. (2007), “A review of research towards computer integrated demanufacturing for materials recovery”, International Journal of Computer Integrated Manufacturing, Vol. 20 No. 8, pp. 773-780.

Xing, K. and Luong, L. (2009), "Modelling and Evaluation of Product Fitness for Service Life Extension" Journal of Engineering Design, Vol. 20, pp. 243-263.

Zink, T., Maker, F., Geyer, R., Amirtharajah, R. and Akella, V. (2014), "Comparative life cycle assessment of smartphone reuse: repurposing vs. refurbishment", International Journal of Life Cycle Assessment, Vol. 19, pp. 1099-1109. 